\title{
La más pobre entre las pobres. Para una crítica de los estudios sobre la Chiquitania (oriente boliviano)
}

\section{Cecilia Martínez}

- CONICET - Consejo Nacional de Investigaciones Científicas y Técnicas, Universidad de Buenos Aires | Buenos Aires, Argentina

$\mathbf{v}$ ceciliagmartinez@gmail.com

\section{RESUMEN}

A partir del análisis comparativo con otras regiones de las tierras bajas de Bolivia, con estudios sobre misiones jesuíticas, y con la historia social boliviana y la etnohistoria andina se señalan los fundamentos historiográficos, políticos y académicos de la escasez de las investigaciones dedicadas a Chiquitos y de la imagen asociada con su patrimonio y su pasado jesuítico. Luego, a partir de evidencia del período colonial tardío (1768-1809), se propone una lectura alternativa sobre los elementos que estructuraban la vida social de los habitantes de Chiquitos. Se toman en cuenta la vigencia de las parcialidades como unidades sociales significativas entre los indígenas de la región, el carácter marginal y fronterizo de la provincia y sus efectos sociopolíticos, culturales y demográficos, y las formas amerindias de asimilación de la alteridad.

DOI

http://dx.doi.org/10.11606/ 2179-0892.ra.2018.145527

\section{PALABRAS-clave}

Chiquitos, chiquitanos, tierras bajas sudamericanas, estudios americanistas, alteridad, frontera 
Hace no mucho tiempo dos especialistas en etnología y etnohistoria del Chaco y la Amazonía de Bolivia escribieron que "las tierras bajas bolivianas son parientes pobres de los estudios americanistas" (Villary Combès, 2012: 7). En línea con esa metáfora, la premisa de este balance similar pero acotado, es que, entre las parientes pobres, la Chiquitania es la más pobre: la prima indigente de los estudios americanistas. Estas páginas son, en primer lugar, una reflexión crítica sobre la escasez de investigaciones sobre historia y antropología de la Chiquitania pensadas en torno de tres ejes de análisis comparativo: a) las investigaciones en historia y antropología de las tierras bajas de Bolivia, b) las investigaciones sobre misiones jesuíticas, y c) la historia social bolivianista y la etnohistoria andina. Chiquitos puede ser considerada como caso de estudio de cada uno de esos ejes (condición que comparte con el Chaco y la Amazonía, con el Paraguay, y con la región andina, respectivamente), sin embargo, no es un exponente significativo de ninguno de ellos. De la comparación con regiones cercanas desde el punto de vista de la distancia geográfica y la afinidad temática, se deducen los fundamentos de la pobreza relativa de las investigaciones dedicadas a Chiquitos. Por otra parte, una serie de condiciones historiográficas, políticas y académicas contribuyeron a reducir a Chiquitos a una imagen asociada con su patrimonio y su pasado jesuítico. Pero el estudio de los documentos del período post-jesuítico no confirma el peso ni la continuidad del legado de la Compañía de Jesús incluso en el momento inmediatamente posterior a la expulsión, al mismo tiempo que revela la incidencia de otros factores que estructuraron la vida sociocultural de la provincia.

En la primera parte analizo los fundamentos de la escasez de estudios sobre Chiquitos y reconstruyo el escenario en el que se forjó la imagen asociada con lo jesuítico. Luego, a partir de evidencia del período colonial tardío (1768-1809), expongo una interpretación alternativa sobre los elementos que estructuraban la vida social de los habitantes de Chiquitos. En ella tomo en cuenta, por un lado, la importancia de las parcialidades en la cohesión e interacción de los grupos indígenas reducidos en los pueblos y, por otra parte, el carácter marginal y fronterizo de la provincia junto con sus efectos sociopolíticos, culturales y demográficos y las formas amerindias de asimilación de las diferencias interétnicas.

\section{UNA EXCEPCIÓN ANÓMALA}

Ya desde la descripción de su ubicación geográfica y de sus características ambientales se advierte la pobreza relativa de Chiquitos en comparación con el Chaco y la Amazonía. Se suele definir a Chiquitos como la franja transicional que separa aquellos dos ambientes. A mitad de camino entre el impenetrable infierno verde y la selva navegable, Chiquitos es la tierra que se define afirman- 
do que no es ni una cosa ni la otra. Ni tan seca y caliente como el Chaco, ni tan fluvial y anfibia como la Amazonía: un justo medio despojado de rasgos fuertes, de temperamento geográfico y ambiental, pero, tal vez gracias a eso, pleno de condiciones para su ocupación. El Chaco y la Amazonía tan extremos en sus características ambientales, se mantuvieron en gran medida inaccesibles para los blancos; fueron lugares de refugio de sociedades indígenas por largo tiempo desconocidas para Occidente y por eso atractivos para los etnógrafos y antropólogos. Por el contrario, el terreno actualmente conocido como la región de Chiquitos o Chiquitania se presentó, desde el inicio de la conquista, asequible para los conquistadores pioneros de América del Sur. Domingo Martínez de Irala fue en 1548 el primero en allanar la comunicación de Paraguay con Charcas atravesándola, luego del intento fallido de uno de sus capitanes de hacerlo por la vía del Chaco, río Pilcomayo arriba; Santa Cruz la vieja, primera ciudad de las tierras bajas de Bolivia, fue fundada en el corazón de la región.

Pero esta entrada temprana de la Chiquitania en la historia fue contemporánea con la conquista del imperio más extenso de América precolombina y con la organización del orden colonial en su núcleo sudamericano: Perú y Charcas. Santa Cruz de la Sierra tuvo que ser trasladada al piedemonte poco después de su fundación. Por ser producto de la avanzada del arco conquistador asunceño, no tardó en entrar en disputa con los gobernantes chuquisaqueños. Así, su condición liminal, su pobreza de recursos minerales y su impronta rebelde resultaron en una marginación notable en el contexto de la colonia que se tradujo luego al campo historiográfico profesional.

Ahora bien, la escasez de investigaciones historiográficas es un rasgo que la Chiquitania comparte con las demás regiones de las tierras bajas bolivianas. Como advirtieran Saignes, Renard-Casevitz y Taylor (1988: 9), en razón de cierta división de tareas disciplinares entre la Historia y la Antropología, la región de los Andes quedó en manos de la primera, que pudo desplegar cómodamente sus herramientas analíticas sobre regiones y sociedades alcanzadas por la cultura occidental. Por su parte, a la segunda concernió lo que sucedía al este del piedemonte, espacio de tiempos, lugares y pueblos asociados con formas de organización social alternativas al Estado. Sin embargo, Chiquitos es una excepción a esa regla por partida doble; una excepción anómala, porque apenas Ilamó la atención de los historiadores, pero tampoco despertó el interés de los antropólogos, lo que explica en gran parte su pobreza en los estudios americanistas. En esta excepción anómala, es grande el peso del pasado jesuítico-reduccional de sus pobladores: de las misiones de los jesuitas resulta que la Chiquitania es demasiado occidental para los antropólogos y demasiado indígena para los historiadores. Los indígenas reducidos en misiones desde una fecha tan temprana como las últimas décadas del siglo XVII se consideran perdidos como objeto 
de estudio etnográfico y de análisis etnológico: la pretendida occidentalización borró todo rasgo de indigenidad. Muestra de ello es la actitud esquiva de los etnógrafos que recorrieron las tierras bajas de Bolivia a fines del siglo XIX y principios del XX. En efecto, Indios y blancos en el Oriente Boliviano y Exploraciones y aventuras en Sudamérica de Erland Nordenskiöld son fuentes preciosas de información sobre los indígenas del Chaco y de la Amazonía. Interesado por registrar lo que consideraba los últimos estertores de auténtica vida indígena, el etnógrafo sueco omitió deliberadamente incluir a Chiquitos en el recorrido de sus viajes. La misma premisa guió a Alfred Métraux en su interés por el Chaco. Sus referencias a Chiquitos (1942) están mediadas por las mismas fuentes de información que critico aquí: los informes de los jesuitas y el relato de viaje de Alcide d'Orbigny. En suma, las primeras décadas del sigloXx, prolíficas en relatos de viajes y descripciones etnográficas sobre los indígenas del Chaco y de la Amazonía, son, por el contrario, un páramo de información sobre Chiquitos y los chiquitanos.'

Por otro lado, en el campo de los estudios relacionados con la Compañía de Jesús en América, quedó apocada en la comparación con el Paraguay, que por su mayor tamaño en cantidad de pueblos y de indígenas reducidos, se constituyó en el paradigma de lo jesuítico en Sudamérica. Para las indagaciones historiográficas interesadas en conocer el modo de operar jesuítico, bastó con estudiar en profundidad aquel caso testigo y saldar la deuda con otras regiones generalizando el modelo paraguayo. En Chiquitos es el caso de las explicaciones sobre el funcionamiento del sistema de la economía misional en las que, por ejemplo, se trasplantó el uso de los nombres en guaraní para distinguir las tierras comunitarias de las domésticas (Hoffmann, 1979: 59; Parejas Moreno y Suárez Salas, 2007: 87-88; Tonelli, 2004: 83). El riesgo de hacer lo mismo con las consecuencias de la expulsión es grande por el acento que suele ponerse en aquello que las asemeja como provincias jesuíticas. Sin embargo, no pudo haber sido más disímil el destino de cada una luego de 1768: mientras en Paraguay se aplicó un programa de liberalización del acceso a la tierra y a la mano de obra indígena, en Chiquitos se decidió la continuidad del régimen reduccional a cargo de curas doctrineros.

Para la historiografía tradicional, por otra parte, el hecho de que fueran indígenas quienes portaban los marcadores sociales y políticos de la cultura occidental y de que lo hicieran en reducciones que funcionaban según el modelo de la "república de indios", alejados de los blancos, implicaba involucrarse con un actor social que le resultaba ajeno. Se podría decir que su indiferencia con respecto al pasado de los chiquitanos se debe al motivo inverso al que alejó a las investigaciones etnográficas de Chiquitos. De ahí que Gabriel René Moreno (1888), el primer historiador de la región, organizara su catálogo de documentos administrativos post-jesuíticos a partir de los períodos de gestión de los gobernadores coloniales e hiciera de las disputas políticas entre éstos, los curas
1 "Chiquitano" es el nombre con el que actualmente se conoce al grupo mayoritario de indígenas que habitan la Chiquitania. Es un etnónimo que proviene de "Chiquitos", provincia jesuítica en los siglos XVI y XVII y luego gobernación militar. A su vez, Chiquitos tomó el nombre del etnónimo quinientista "chiquitos", traducción al castellano de "tapuy mirí" que es la forma en que los guaraní-hablantes se referían a los indígenas que habitaban la región delimitada por los ríos Cuapay, Paraguay y los 18 y 15 grados de latitud sur. Dado que se trata de palabras en castellano, al referirme a los chiquitanos en plural, utilizo la forma castellana, es decir, con-s final. Pero cuando me refiero a nombres de grupos o de parcialidades en lenguas vernáculas (los morotoco, los boro o los quimeca), no agrego la -s final porque en la mayoría de los casos incluyen la marca del plural correspondiente. De hecho, -ca indica plural en el dialecto tao de la lengua chiquita. Para un análisis de la relación entre la etnonimia y la toponimia de chiquitos, Chiquitos, chiquitanos y Chiquitania, ver Martínez (2015a). 
doctrineros y los administradores seculares - es decir, entre actores sociales blancos-el entramado principal que explicaba la historia de Chiquitos. ${ }^{2}$ Algo similar sobre esta consideración exclusiva del actor social europeo puede decirse de la obra de Enrique Finot (1939) y Enrique de Gandía (1935), interesados en reconstruir la conquista del Oriente boliviano y dirimir en el campo de los estudios historiográficos la disputa entre Paraguay y Bolivia por el Chaco Boreal.

En efecto, la renovación historiográfica de mediados del siglo XX no alcanzó al Oriente boliviano en general ni a Chiquitos en particular. Fue la región andina la que, por ser el centro del sistema colonial y escenario de rebeliones indígenas, se ajustaba mejor a los requisitos para convertirse en objeto de estudio de la historia social. Luego, la abundancia de crónicas de conquistadores que hacían referencia al pasado inca junto con la documentación sobre los indígenas quechua y aymara en el período colonial hicieron lo propio con la etnohistoria a partir de 1950. Con la Revolución de 1953, esos mismos pueblos se convirtieron en el paradigma del campesinado indígena boliviano, a la vez que, en contextos mineros y urbanos, se ajustaban satisfactoriamente a las categorías "clase obrera" " "sectores populares" tan caras a los historiadores. No ocurría lo mismo con los chiquitanos, cuyo recorrido histórico como pueblo indígena y cuyo destino a mediados del siglo pasado eran prácticamente desconocidos para la comunidad académica.

\section{CIRCUNSTANCIAS DE UNA POBREZA RELATIVA}

Por supuesto que estas generalizaciones no pretenden transmitir la idea de un vacío total de publicaciones sobre el pasado o sobre los indígenas de Chiquitos. Mencioné la obra pionera de Gabriel René Moreno, y los clásicos libros de Enrique Finot y Enrique de Gandía. Agrego la tesis de José María García Recio (1988), gran aporte para el conocimiento del siglo XVII cruceño. También son insoslayables las referencias de Branislava Susnik (1978) en torno del poblamiento prehispánico de la región y las investigaciones de Jürgen Riester (19671968, 1976, 1986), prácticamente el único antropólogo que hizo trabajo de campo etnográfico y elaboró vocabularios y gramáticas modernos de bestro ${ }^{3}$. A Birgit Krekeler (1995) y a Barbel Freyer (2000) debemos los primeros esbozos para una historia de los chiquitanos. Sin embargo, el conjunto de estas publicaciones estuvo lejos de revertir la carencia de investigaciones americanistas sobre Chiquitos a lo largo de los siglos XIX y XX, sobre todo en lo que concierne a su carácter profesional, sistematicidad y articulación. ${ }^{4}$

Ahora bien, ese vacío que los investigadores profesionales fueron reacios a llenar dio lugar a un campo de producción destinada al gran público muchas veces orientado a enmarcar y acompañar ciertos proyectos de aplicación práctica.
2 Recientemente, la periodización y las premisas de su catálogo fueron replicados en obras de síntesis histórica sobre Chiquitos (Roca, 2001; Tonelli, 2004) a pesar de datar de una fecha tan temprana como 1888. Llamativamente, prescindieron de la lectura y del análisis de los documentos catalogados por el propio Moreno.

3 Besiro es el nombre dado en años recientes al idioma chiquito.

4 En los últimos años esta tendencia fue notablemente revertida por las investigaciones de Isabelle Combès (2006, 2008, 2009, 2010, 2011, 2012) y de Catherine Julien (2005), fundamentalmente en lo que respecta al período prejesuítico. 
Además, las obras en cuestión saciaron en gran medida la avidez de los pobladores del Oriente boliviano de una historia propia para contar y sobre la cual construir identidad. Sin embargo, se caracterizan por una peculiaridad llamativa: todas ellas asocian a Chiquitos con la herencia del pasado jesuítico-misional desde el siglo XVIII hasta el presente. Fundación de las reducciones de Chiquitos, de Antonio Menacho (1987), Las misiones jesuíticas de Chiquitos, de Pedro Querejazu (1995), Chiquitos: historia de una utopía, de Parejas Moreno y Suárez Salas (1992), como tantas otras obras publicadas mayoritariamente en la década de 1990 (Cumucio, 1994; Ruiz, 1998; Cisneros y Richter, 1998; Khune, 1996, 2007; Parejas Moreno, 2007), se detienen exclusivamente en el período jesuítico. Describen la metodología misional y la organización de las reducciones. Al mismo tiempo, trazan una línea de continuidad entre el siglo XVIII y el legado arquitectónico y cultural del presente que también encuentran reflejado en la identidad actual de los indígenas. Aunque no es una imagen que falte por completo a la verdad histórica, requiere ser revisada a partir de las circunstancias en las que se forjó y de las implicancias políticas, sociales y académicas que acarrea.

Que el período que se extendió entre 1691 y 1768 y la imagen jesuítico-misional hayan sido los que trascendieron se debe, en primer lugar, al tipo de evidencia disponible para conocer la región, a su abundancia y a la buena calidad de información que aporta. La relación historial del padre Juan Patricio Fernández, el informe del padre Julián Knogler, las propias cartas anuas de la provincia, las gramáticas y vocabularios de la lengua chiquita, entre otros, conforman un gran corpus de documentos a través de los que es posible conocer en detalle los métodos y acciones de las misiones y reducciones de indios. Los escritos más públicos y difundidos de los Padres de la Compañía de Jesús daban testimonio de acciones edificantes y de resultados ejemplares de sus misiones con objetivos ante todo apologéticos. El contraste con la información sobre el período posterior a la expulsión es flagrante. De ahí que, en su catálogo comentado de los documentos oficiales, Gabriel René Moreno no escatimara en denuncias del desfalco económico y de la decadencia moral de la provincia y responsabilizara por ello a la falta de escrúpulos de los curas doctrineros y a los gobernadores coloniales por su negligencia o su consentimiento. Moreno se basaba también en las apreciaciones del naturalista francés Alcide d'Orbigny quien registró la diferencia entre lo que había leído de la pluma de los jesuitas con lo que encontró en su visita a la provincia en 1831: la falta de recursos y la decadencia moral, sobre todo de las mujeres. Pero, así como d'Orbigny advertía "un estado de prosperidad tan inferior", encontró "intactas" las instituciones administrativas y religiosas que los jesuitas dejaron en el momento de la expulsión. Al respecto afirmó, nada menos, que "bajo otros hombres, volví a encontrar en la provincia el régimen de las misiones en su integridad" (1945: 1268). Moreno también se 
hizo eco de esta evaluación y ambas apreciaciones, es decir, la de la decadencia post-jesuítica y la de la continuidad del régimen misional fueron luego reproducidas en las síntesis históricas de Roca y Tonelli a principios del siglo actual. Por eso, entre la escasez de información sobre el período anterior a la llegada de los jesuitas y el desorden de la administración colonial secular, no sorprende que el momento jesuítico sea considerado la Edad de Oro de la Chiquitania. Es visto como un momento fundacional no solamente en lo que a sus instituciones respecta, sino también a la identidad sociocultural de sus indígenas. Se ha escrito por ejemplo que, en el período jesuítico, nació “una 'nueva cultura' que Ilamamos 'cultura chiquitana reduccional' [...] producto de la asimilación e integración de las diversas culturas chiquitanas [...] bajo la guía cristiana jesuítica" que llega hasta el presente (Tomichá, 2002: 300). En la misma línea de reconocimiento del peso de la evangelización jesuítica, también se afirmó que en la actualidad los chiquitanos encarnan una "nueva cultura indígena-cristiana" en la que "el legado jesuita se ha mantenido como un amplio conjunto de tradiciones culturales" (Strack, 1992: 2 y 45). Los detractores de la evangelización, por su parte, entendieron el fenómeno en términos de sincretismo: la aculturación cristiana era una apariencia tras la cual resistían las antiguas creencias y prácticas religiosas indígenas (Riester, 1976). Superficial o profunda, para quienes se dieron a la tarea de definir qué es lo chiquitano, el punto de partida ineludible es la evangelización de los indígenas realizada por los jesuitas; el de llegada, una nueva cultura indígena que pervivió más allá-y a pesar-de la expulsión hasta la actualidad. Sus rasgos diacríticos serían la asimilación de la vida política y citadina por parte de los indios, la vigencia del cabildo indígena, el culto devoto de los santos patrones de los pueblos y las festividades cristianas y la adopción de los criterios occidentales del uso del tiempo y del espacio inculcados por los jesuitas. No menos importante fue la homogeneización lingüística de todos los indios reducidos bajo el dialecto tao de la lengua chiquita en detrimento del uso de los demás dialectos y lenguas preexistentes. Todos estos signos se habrían mantenido intactos hasta el presente con excepción de la lengua, reemplazada por el castellano.

Una evaluación semejante resulta por lo menos curiosa si se tiene en cuenta la información referida a la diversidad étnica de la región que legaron los propios jesuitas. El perfil humanista de los padres de la Compañía de Jesús hizo de sus registros una fuente invaluable de datos por su sensibilidad y precisión etnográficas sobre los indígenas que encontraron en sus misiones y redujeron en pueblos. En las relaciones e informes que escribieron, dan cuenta de la forma de vida de los indios, desde su vestimenta y utensilios hasta las actividades cotidianas y creencias. ${ }^{5}$ Pero de todos los datos disponibles, lo que resulta realmente abrumador es la infinidad de nombres con los que se hace referencia
5 Sobre la importancia de las fuentes jesuíticas para el conocimiento de las poblaciones indígenas de América ver Métraux (1944). Sobre las características generales de la evangelización jesuítica y la casuística de Chiquitos en particular, ver Martínez (2015b). 
a los grupos que poblaban la región. Fue a propósito de ella que Alfred Métraux (1942: 114) sentenció que deslindar su pertenencia lingüística era la tarea más desalentadora de la etnología americanista. Esta abundancia de nombres no es, no obstante, exclusiva del registro jesuítico: ya proliferaban desde el siglo $\mathrm{XVI}$, cuando los conquistadores pioneros recorrieron la región por primera vez y repartieron parcialidades de indios en encomienda en la fundación de Santa Cruz de la Sierra la vieja (Documentos referentes..., 2008; Combès, 2010). Aunque el análisis comparativo de los etnónimos del siglo XVI con los del XVIII todavía aguarda una indagación exhaustiva, parece existir cierto patrón según el cual las raíces de los nombres se repiten mientras que su desinencia varía de -coci a -ca, sufijos que indican, respectivamente, el plural que tal vez provenga de la lengua que hablaban los gorgotoqui de Santa Cruz la vieja y de la del dialecto tao de la lengua chiquita. Es probable que esas marcas lingüísticas fueran indicadores del escenario sociocultural e interétnico de la región, por ejemplo, del predominio del grupo que hablaba una lengua por sobre los demás grupos o de la difusión de una lengua, producto del alto nivel de comunicación e intercambios entre ellos (Combès, 2006, 2012). Los jesuitas montaron su proyecto sobre el estado de cosas que encontraron al llegar para implementar la homogeneización lingüística que caracterizó su política misional en la provincia de Chiquitos. Es probable que el mismo criterio fuera adoptado para elegir los sitios donde fundar los pueblos de reducción.

A pesar del antecedente de semejante pluralidad de nombres, sin dudas correlativa con un escenario interétnico y lingüístico también diverso, dinámico y fluido, lo que quedó grabado a fuego en el imaginario sobre Chiquitos es el advenimiento de una cultura nueva producto de la experiencia misional de los indígenas. Se dio por sentado que la acción misionera de los jesuitas fue lo suficientemente potente como para hacer tabla rasa de la diversidad preexistente y forjar sobre ella la marca indeleble y duradera de lo cristiano y lo occidental. Por eso, luego de haber puntualizado lo relativo a la disponibilidad y calidad de las fuentes de información, analizaré las condiciones académicas y políticas que hicieron posible que fuera esa imagen la que trascendiera sobre Chiquitos.

\section{LA UNESCO Y LA DOXA}

Al menos dos factores confluyeron en la idea de la síntesis jesuítica chiquitana. El primero, local, fue la declaración en 1990 como Patrimonio Cultural de la Humanidad por la UNESCO de seis pueblos de la Chiquitania. El pronunciamiento de ese organismo coincidió con la última etapa de restauración y de reconstrucción de los templos que había comenzado en la década de 1970, impulsadas por el Vicariato de Ñuflo de Chávez y dirigido por el arquitecto suizo y jesuita Hans 
Roth. Esa puesta en valor fue, a su vez, una inquietud que desde la primera mitad del siglo XX manifestaron el jesuita suizo Félix Plattner, interesado en rescatar el legado de su compatriota Martín Schmid (quien construyera las iglesias en el siglo XVIII) y Plácido Molina Barbery quien, enterado de su existencia en un recorrido por la región como funcionario de límites, se preocupó por salvarlas de su inminente derrumbe por falta de mantenimiento. En el proceso de restauración de la iglesia de San Rafael se encontraron partituras de música barroca que interpretaban los indígenas en la época jesuítica. El hallazgo promovió la creación de un archivo en Concepción, sede del vicariato de Ñuflo de Chávezy, desde 1996, la celebración bienal del Festival Internacional de Música Renacentista y Barroca Americana Misiones Jesuíticas de Chiquitos, donde se interpreta la música de las partituras del siglo XVIII (Page, 2008, 2012; Parejas Moreno, 2006).

Con sus iglesias y su acervo documental pero también con sus habitantes, la región se convirtió en el testimonio vivo del barroco americano, amalgama armoniosa y equilibrada de lo europeo y lo indígena. Fue así como el rescate, la conservación y la restauración de los patrimonios arquitectónico y musical forjaron una imagen de la Chiquitania basada en su pasado jesuítico. La declaración de la UNESCO no hizo otra cosa que potenciar los efectos del proceso de puesta en valor patrimonial. De esta época datan las principales obras de divulgación sobre el período jesuítico y el punto de partida de las investigaciones sobre musicología, artes y arquitectura. ${ }^{6}$

Este proceso local coincidió con un contexto político internacional, con un paradigma teórico y con una doxa académica que le dieron sentido. Íntimamente asociados entre sí, constituyen el otro factor que permitió forjar la imagen jesuítica de la Chiquitania. En efecto, la declaración como Patrimonio Cultural de la Humanidad es contemporánea con el Quinto Centenario del descubrimiento de América y la idea del encuentro de dos mundos. Eran también los años del fin del mundo bipolary del desmembramiento de la Unión Soviética. La antropología y la historia habían abandonado las ideas de cultura, aculturación y resistencia para explicar el efecto de la conquista y la colonización europea sobre los indígenas y hablaban con soltura de agencia, etnogénesis y estrategias indígenas. Con esos conceptos procuraban transmitir la idea del dinamismo del contorno, de la forma y del contenido de los grupos étnicos, así como también su participación activa en la conformación de los regímenes coloniales. Partiendo de la existencia de relaciones interétnicas en las que unos dominan y otros son dominados, les atribuían a las poblaciones indígenas un papel activo en la creación, la configuración y la definición de su propia identidad. Por el efecto de la interacción en un contexto colonial, las unidades de identidad indígena se formaban con elementos antiguos propios y elementos nuevos provenientes tanto de terceros grupos dominados como de quienes los dominaban. Así, a una idea
6 Involucrados activamente en la presentación del pedido ante la UNESCO, Alcides Parejas Moreno y Virgilio Suárez Salas (1992), y Pedro Querejazu (1995), acompañaron el resultado exitoso de la gestión con la publicación de sendos libros sobre el período jesuítico chiquitano desde una perspectiva patrimonial. A ellos se suman las numerosas investigaciones en el área de Historia del Arte que tomaron la música y la arquitectura del jesuítico chiquitano como caso testigo del barroco americano, por ejemplo, Waisman (1991). 
de cultura rígida, concebida como un conjunto de rasgos diacríticos contraponían esta otra concepción de la identidad étnica fluida y cambiante. De ahí que se acuñara el concepto etnogénesis para dar cuenta del surgimiento de ciertos grupos indígenas a causa de fusiones, de divisiones o de la adopción de algún elemento o pauta sociocultural por difusión o por mutación endógena, producto de la incidencia directa o diferida de la conquista europea. Desde la década de 1990 en adelante este paradigma teórico e interpretativo fue efectivo para dar cuenta del origen y del devenir de numerosos grupos étnicos en las fronteras de los dominios coloniales, en general reacios a la conquista como los chiriguano o los mapuche por mencionar solamente dos ejemplos entre tantos? ${ }^{7}$.

En el mismo sentido, aunque con resultados distintos, se orientó una vertiente de investigaciones en etnohistoria andina para explicar la participación activa-estrategia, agencia-de los indígenas en su integración al orden colonial. Esas investigaciones mostraron, por ejemplo, cómo ciertos curacas andinos se aliaron a los conquistadores españoles para librarse de la dominación incaica. A partir de ellas también se sabe que los curacas adaptaron los relatos míticos sobre el origen de los incas a la demanda de pruebas para la legitimación de su liderazgo en el nuevo orden colonial y a los principios de sucesión castellana. Otros autores señalaron el surgimiento de nuevos liderazgos que le disputaron la legitimidad a los caciques tradicionales, basados en la conformación de los cabildos indígenas y en el sistema de fiesta-cargo de las cofradías de culto a los santos, creados con las reducciones toledanas (Stern, 1982; Urton, 1990, Abercrombie, 1998). En suma, desde diferentes perspectivas abordaban el destino de las autoridades tradicionales andinas en el marco de un régimen colonial modelado por las reformas toledanas del que participaron de manera activa pero que paradójicamente, en algunos casos horadó su legitimidad y su liderazgo.

Al tratarse de una región colonizada en una zona de frontera, era esperable que los estudios sobre Chiquitos conjugaran ambas vertientes. Por un lado, la idea de lo chiquitano como síntesis jesuítico-indígena se sumó al conjunto de ejemplos de etnogénesis, en este caso un ejemplo de etnogénesis misional, en el sentido de conformación de una nueva unidad de identidad indígena por efecto directo de la colonización jesuítica (Tomichá, 2002; Radding, 2005). Resulta paradójico, no obstante, que una herramienta conceptual que apela al dinamismo haya servido para postular el nacimiento de una identidad indígena cristalizada y perenne.

Por otro lado, la casuística andina referida a la participación de los liderazgos indígenas precolombinos en la dominación colonial y a los efectos sociopolíticos de las reducciones de indios también tuvo eco en las publicaciones sobre Chiquitos. En Paisajes de poder e identidad, Cynthia Radding se ocupó, entre otras cosas, de mostrar el funcionamiento de la cultura política en los pueblos de indios de Chiquitos. Al respecto afirmó que ésta "se configuró por
7 En el problema de la definición de los grupos étnicos y sus fronteras, Fredrik Barth (1969) fue considerado pionero con su introducción al libro así titulado; una crítica a la originalidad atribuida a esa idea fue planteada por Diego Villar (2004) quien remite a Evans-Pritchard, Dumont y "la pléyade estructuralista" en lo que al carácter relativo de las definiciones de los grupos se refiere. Villar destacó como original y pionera, en cambio, la racionalidad que Barth atribuye a los individuos pertenecientes a pueblos indígenas a la hora de definir su pertenencia identitaria. Exponentes etnográficos clásicos de esta vertiente son los trabajos de Cardoso de Oliveira (2003). El capítulo de Schwartz y Salomon (1999), por su parte, resume esta última tendencia en clave etnohistórica y la ilustra con ejemplos de distintas partes de América. Una reflexión de síntesis también se encuentra en Boccara (2005). Otro autor ineludible al respecto es Cruzinski (2007). Sobre la etnogénesis, chiriguano véase Combès y Saignes (1991), sobre la mapuche, véase Boccara (1999). 
medio de esferas rivales de autoridad dentro de las comunidades", que se "adaptaron modos de liderazgo anteriores a la conquista a los cargos que las autoridades coloniales establecieron en las misiones" y que "las figuras de autoridad tradicional tenían acceso preferencial a los cargos políticos de las misiones" (Radding, 2005: 198 y 210). Aunque verosímiles en el marco teórico referido, esas afirmaciones no se confirman con la evidencia documental de primera mano. Si bien es innegable que en Chiquitos se formaron cabildos que realizaban las demandas, denuncias y reclamos de los indígenas de los pueblos ante los gobernadores, su situación apenas se ajusta a la agenda andina sobre el papel y las transformaciones de los caciques tradicionales, a causa de las sensibles diferencias que existían entre los liderazgos precolombinos de ambas regiones. Por eso las afirmaciones de Radding tienden a abreviar el pasado reduccional de los indígenas de Chiquitos a una imagen creíble pero no cierta. Más aún: al suponer la similitud con el mundo andino en lo que a las formas de liderazgo se refiere, el antecedente precolombino queda trastocado: se asumen liderazgos permanentes y jerarquías de linajes donde en verdad eran aleatorios y efímeros. El modelo usado como paradigma, en lugar de como herramienta, impone en bloque las preguntas y las respuestas y anula la especificidad de la propia región estudiada y las peculiaridades de sus habitantes y sistemas socioculturales.

Entonces, la pobreza de los estudios americanistas sobre Chiquitos es el resultado de un conjunto de circunstancias documentales, históricas, políticas y teóricas, algunas propias y locales y otras derivadas de la comparación con otras regiones. Su colonización temprana, probablemente facilitada por su condición de justo medio ambiental entre el Chaco y la Amazonía, fue motivo de descarte por parte de los antropólogos. Desde fines del siglo XIX los viajeros, filántropos, naturalistas y etnógrafos fueron esquivos a Chiquitos y a los chiquitanos. Los informes jesuíticos y el relato de viaje de Alcide d'Orbigny se volvieron prácticamente la única fuente de información sobre su pasado, con lo cual, el contraste de calidad, cantidad y contenido entre los documentos jesuíticos y los del período posterior a la expulsión facilitó la idealización del trabajo de los padres de la Compañía de Jesús. La evaluación de 1831 de Alcide d'Orbigny, por su parte, confirmó el carácter fundacional de las misiones jesuíticas en Chiquitos tanto desde el punto de vista institucional como cultural. El catálogo de Gabriel René Moreno no hizo más que revalidarlo.

Tal vez por eso en el siglo XX las iglesias en mal estado de conservación y en peligro de derrumbe no fueron leídas como símbolos de decadencia de lo misional y de lo jesuítico sino como la marca de su persistencia. El afán de suizos y jesuitas contemporáneos de homenajear a sus compatriotas y correligionarios de antaño y el de notables cruceños por reivindicar el pasado local, hicieron la otra 
parte del trabajo de gestión para la reconstrucción de los templos. La búsqueda del reconocimiento internacional de la restauración terminó de cristalizar una imagen de Chiquitos que, mientras pone en valor parte de su patrimonio cultural, paradójicamente, reduce su historia a ochenta años de los al menos cinco siglos documentables.

La comparación con regiones próximas por cercanía geográfica o semejanza histórica no se tradujo en un incentivo para explorar lo que hace de la Chiquitania una región peculiar - o del chiquitano un pueblo distintivo -, sino en un ejercicio de simple trasposición y de confirmación de modelos pensados para otras latitudes. Perspectivas bien dotadas de teorías, conceptos y bibliografía tal vez pertinentes, lejos de enriquecer el análisis, lo empobrecen al homologarlo con situaciones privilegiadas por la historiografía a causa de su condición de "caso testigo": de los jesuitas, en Paraguay, o del corolario sociopolítico de las reducciones de indios en el Alto Perú. Nuevamente, Chiquitos difícilmente se ajuste a alguno de ellos o a cualquier otro "caso testigo" foráneo.

¿A qué se ajusta Chiquitos entonces? ¿A lo jesuítico y lo misional? ¿La restauración de las iglesias y el rescate del acervo musical de la época de los jesuitas son correlativos con la restauración y el rescate de la "cultura chiquitana jesuítico misional"? ¿Es equiparable el estatuto del patrimonio cultural y documental con el de la identidad de un pueblo? Si la identidad chiquitana persistió más de dos siglos y trascendió las condiciones que le dieron origen ¿qué impide pensar que lo mismo haya ocurrido con las identidades prejesuíticas? Pero en cambio, si la relación entre los indígenas y los jesuitas transformó el escenario étnico de Chiquitos y dio origen a una nueva identidad, sostener su pervivencia hasta el presente ¿no supone acaso que los chiquitanos se mantuvieron aislados de toda interacción hasta hoy?

En las próximas páginas presentaré evidencia para una lectura alternativa al canon dominante sobre Chiquitos a partir del análisis de información sobre el período que se extiende desde la expulsión de los jesuitas en 1768 hasta los primeros años del siglo XIX. Me concentraré en señalar situaciones que refutan la pretendida homogeneización del escenario étnico chiquitano y su inmovilización sociocultural y en ofrecer glosas para entender esa realidad histórica. Tomaré en cuenta, por un lado, los datos a favor de la vigencia de las parcialidades y, por el otro, los indicadores de interacción de los indígenas con otros actores sociales, blancos y negros, que me permitirán afirmar el peso de la condición fronteriza de Chiquitos por sobre la tradicional jesuítico-misional. En virtud de ello aportaré una interpretación alternativa a la andina, propia de una dinámica colonial periférica en torno de la conformación de jerarquías indígenas. 


\section{PARCIALIDADES DE INDIOS}

En los pueblos de las misiones de Chiquitos el espacio urbano estaba dividido entre las naciones o parcialidades que formaban la población de cada uno. Como fue señalado, el área que luego formó el territorio de la provincia jesuítica de Chiquitos estaba poblada por una infinidad de grupos que fueron clasificados entre distintas familias lingüísticas: chiquito, zamuco, otuqui, guaraní y arawak. Mientras que la pertenencia a la misma familia lingüística no indicaba necesariamente una autoadscripción al mismo grupo, las personas pertenecientes a una misma parcialidad sí parecen haber sido realmente cercanas, probablemente en virtud de lazos de parentesco que las unían. Es difícil precisar qué eran o cómo estaban conformadas exactamente esas parcialidades. A partir de la información disponible en los documentos se las puede caracterizar como unidades sociales significativas preexistentes a la reducción jesuítica. Es probable que fueran grupos de familias emparentadas entre sí tal vez por medio de matrimonios entre sus integrantes. Sin embargo, hasta la fecha desconocemos las pautas que seguían las uniones matrimoniales entre los indígenas de Chiquitos por lo que cualquier afirmación al respecto es arbitraria. Lo que se sabe es que los jesuitas se valieron de los lazos que existían entre los integrantes de cada parcialidad para lograr que quienes se iban reduciendo en los pueblos atrajeran a los que permanecían en el monte (Knogler, 1979: 148 y 163; Cortesão, 1955: 195-196; Matienzo et al., 2011: 100, 198, 200, 301 y 383; Martínez, 2015b). Luego, las parcialidades fueron la base de la organización de los indígenas reducidos en los pueblos. Los integrantes de la misma parcialidad construían sus casas en la misma calle para conservar la cercanía residencial y la cohesión del grupo.

La tesis de la homogeneización cultural y lingüística sostiene que esa pluralidad de "naciones" se fue borrando progresivamente y que en la medida en que los jesuitas generalizaron el uso del dialecto tao de la lengua chiquita, los indígenas reducidos fueron abandonando el uso de sus anteriores lenguas (d'Orbigny, 1945: 1153, 1161, 1173 y 1190). Por otra parte, hay quienes negaron la genuina existencia de las parcialidades a las que atribuyeron una entidad ficticia. Se adujo (aunque no se documentó) la existencia de "indicios según los cuales las parcialidades habrían asumido sus identidades en el proceso de reducción" para distinguir a los grupos recién llegados a los pueblos de los que ya estaban reducidos. También se afirmó que los nombres y los correspondientes grupos, con "connotaciones ocupacionales o geográficas" (Radding, 2005: 173), dado que compartían la misma cultura material, los mismos rasgos socioculturales y muchos la misma lengua, remitían a distinciones artificiales.

Ninguno de los dos argumentos basta para explicar por qué, en el censo de 1768, realizado inmediatamente después de la expulsión de los jesuitas y veinte 
años después de finalizadas las misiones por no haber más pueblos por reducir, la población fuera registrada en parcialidades (CRM MyCh $24 \mathrm{VII}{ }^{8}$

Por otra parte, en el registro oficial a veces se mencionan los nombres de las parcialidades, y las circunstancias en las que son referidos podrían revelar el sentido que seguía teniendo la distinción entre unas y otras. Por ejemplo, en 1771 se inició un expediente sobre el traslado del pueblo de San Juan porque el lugar donde había sido instalado por los jesuitas doce años antes no rendía buenas cosechas. A causa de ello, "la nación morotoca se había retirado a la montaña inmediata obligada de la necesidad" mientras que los boro se habían mudado a otro paraje más fértil (CRM MyCh $23 \mathrm{XXXI}$ ). Ante esta situación el gobernador Pérez Villaronte propuso abandonar San Juan y repartir la gente entre los pueblos vecinos, pero los indios se opusieron porque "el repartirlos de pueblo en pueblo era acabarlos porque se precisó los habían de apartar a los hijos de los padres, a los hermanos de las hermanas, cuñados, suegros, etc." (GRM MyCh $31 \mathrm{XIX)}$. A pesar de que finalmente se decidió el traslado del pueblo al paraje donde se habían instalado los boro (también Ilamados "la nación bora"), la parcialidad de los morotoco se manifestó más volátil. En 1782, el gobernador Juan Barthelemí Berdugo afirmaba que la mitad de los morotoco de San Juan se encontraban establecidos en Villa María del reino de Portugal (ALP MyCh 253). Los que se quedaron en 1788 reiniciaron el pleito sobre el emplazamiento del pueblo de San Juan. En esa oportunidad, le comunicaron al gobernador que habían retornado al antiguo pueblo (taperas) de San Juan porque la idea de irse, que ellos nunca consintieron, había sido de la parcialidad de los boro. Decían que en esas taperas tenían todo lo que necesitaban, mientras que el pueblo nuevo estaba en una zona muy inundable y carecía de maderas y cañas para construir las casas. La carta, aunque escrita en chiquito - lengua institucional de los cabildos indígenas de la provincia -, fue firmada por los representantes de los morotoco, reconocibles por la terminación de sus apellidos (que comparten con todas las parcialidades zamuco): Juan Tacunade, teniente, José Cosiñetide, alférez, Juan Copeciade, alcalde de segundo voto y Francisco Pareyode. Por su parte, los boro se resistieron a abandonar el pueblo nuevo porque ya habían hecho ahí sus chacras y sus chozas (MyCh GRM 31 XIX).

Es posible que esta diferencia entre boro y morotoco, quienes según las taxonomías modernas pertenecen a dos familias lingüísticas distintas, chiquita y zamuca, haya sido la manifestación de una rivalidad que les impedía vivir en el mismo pueblo. Por otra parte, uno de los curas que informaba sobre esta situación decía que los morotoco no tenían asiento fijo, que se iban siempre al monte y que, de esa manera, evitaban el trabajo de hacer las chacras y sementeras porque allí se alimentaban con el fruto de las palmas de totai (GRM MyCh $31 \mathrm{XIX)}$. En efecto, eran un grupo chaqueño para el cual la movilidad relativa era
8 El censo en cuestión consta de más de 300 folios en los que fueron registrados los nombres y apellidos de los habitantes adultos, hombres y mujeres, de los diez pueblos de la provincia. El padrón de cada pueblo está antecedido por un cuadro que resume las cantidades de habitantes agrupados por parcialidades y discriminados por sexo. La lista de los nombres de los indígenas también sigue el criterio de registro por parcialidades y por sexo. En San Xavier las parcialidades son: quimecas, punacicas, piococas, quibuquicas, payconecas y guarayos; en San Rafael: mataucas y veripones; en San José: piococa, maxamaroca y penoqui; en San Juan: boros, morotocos, tomoenos, paronos, cucarates y caipodorates; en Concepción: anapareca, boocooca, cusica, sibacas, yurucariquia, quimomeca, tapacuraca, quitemos, napecas y paiconeca; en San Miguel: basorocas, pequicas, guaraios y parabacas; en San Ignacio: tanepicas, yamanuca, cusicas, piococas, guberecas y guaboyos; en Santiago: boros, ugaronocas, tunachoca, caipodorades e imonocas; en Santa Ana: basorocas, zarabecas, curuminacas y ecorobarica o cobareca; y en Santo Corazón: mataucas, boros y otuques. 
una forma de vida que evidentemente los jesuitas no habían llegado a erradicar. El caso muestra además que incluso para el registro oficial las parcialidades seguían teniendo sentido porque delimitaban grupos que se diferenciaban en situaciones prácticas y concretas, tales como la elección de dos sitios distintos para emplazar el pueblo o la migración al reino de Portugal. Por otro lado, es significativo que para los propios indígenas el eventual reparto de las parcialidades entre los pueblos vecinos significaba su fin en la medida en que cortaba los lazos que unían a sus integrantes. De hecho, esos lazos eran el cimiento de la cohesión de las parcialidades y el motivo por el cual sus integrantes se movían en conjunto. Al ejemplo de los boro y de los morotoco se suma el de "toda la parcialidad de los covareses" del pueblo de Santa Ana que en 1772 "se ha desaparecido con su capitán y cabos sin quedar ninguno" en muestra de disconformidad con la calidad y la cantidad de los efectos de fomento con los que los pretendían recompensar por la recolección de cera y por el hilado de algodón (GRM MyCh 23 XXXIII).

Al parecer la movilidad de las parcialidades o de grupos de familias pertenecientes a la misma parcialidad era fluida. Lejos de haber quedado paralizados en los pueblos una vez reducidos, los indígenas de Chiquitos se movían de un pueblo a otro, del pueblo al monte, del reino de España al de Portugal y en muchos casos lo hacían en bloques de familias y de parcialidades. La parcialidad quimeca lo ilustra con claridad. El censo de 1768 no registra parcialidades quimeca más que en el pueblo de San Xavier. Pero apenas un año después, a propósito de un episodio ocurrido durante la visita de una comitiva de portugueses a la provincia, el cura de San Ignacio, Simón Vera y Gallo, dijo que de no haber trasladado a los portugueses de San Ignacio a Concepción y de no haberse encontrado el gobernador en este último pueblo, aquellos "hubieran perecido a manos de la belicosa nación quimeca" por el "odio y total aborrecimiento que como vínculo hereditario les han dejado sus antepasados en memoria del cruel estrago y cautiverio que padecieron sus miserables familias bajo el yugo de los mamelucos" (ALP MyCh 97). Es decir que los quimeca se habían mudado a los pueblos de Concepción y de San Ignacio. En efecto, en 1785 el gobernador Cañas certificaba a favor de sus méritos y servicios a la corona haber logrado que una familia de la parcialidad quimeca volviera de Concepción a San Xavier (CRM MyCh 27 I). Con "el estrago y cautiverio" se referían al ataque que los mamelucos hicieron al pueblo de San Xavier en el año 1696 en el que mataron y esclavizaron a muchos de los indígenas reducidos. Nuevamente, en el ejemplo quimeca la parcialidad aparece asociada con la solidaridad fundada en los lazos de parentesco y relacionada con la movilidad y la migración, a causa de su carácter cohesivo. Agreguemos además que es una condición compartida por parcialidades de diversa filiación lingüística porque los morotoco hablaban zamuco, los boro hablaban tao (dialecto chiquito), los curucané, una lengua otuqui y los quimeca, piñoca (dialecto chiquito). 
De lo dicho hasta acá se desprende que las parcialidades eran unidades socialmente significativas entre los indígenas que vivían en los pueblos de Chiquitos. La diferenciación de esos grupos refleja que, entre quienes el canon tradicional incluiría dentro del gran conjunto homogéneo de los chiquitos creado por los jesuitas, existían fricciones y relaciones de fuerza. La diferencia entre unas parcialidades y otras era tal, que la interacción con el mismo actor podía desenvolverse de formas opuestas: mientras la mitad de los morotoco se había mudado a Mato Crosso, capitanía del reino de Portugal, los quimeca no dudaban en vengar el estrago de sus parientes a manos de los portugueses. Pero al mismo tiempo que los contornos de los grupos se definían con nitidez en la interacción con otros en igualdad de condiciones, también operaban relaciones de parentesco intrínsecas que los hacían moverse en bloque. En circunstancias en las que afloraban las diferencias entre las parcialidades, el mapa etnográfico de la provincia de Chiquitos se presenta más diverso y múltiple que lo que la imagen de la homogeneización es capaz de transmitir. Eso no significa, sin embargo, que la referencia a todos los indígenas de las distintas parcialidades como "chiquitos" fuera ficticia o inventada. Efectivamente existía un registro institucional colonial que los homologaba en tanto habitantes de los pueblos de la misma provincia. En la medida en que no se presentaran situaciones que ameritaran la distinción, todos formaban parte del mismo gran conjunto.

Es decir, que las parcialidades fueran una realidad palpable en situaciones como las que describí no necesariamente niega la jurisdicción colonial de la provincia ni su pasado jesuítico. Como se vio, el cabildo era una institución que efectivamente funcionaba y la lengua chiquita la herramienta de comunicación oficial de los indígenas con las autoridades, incluidos los de la parcialidad morotoco que hablaban zamuco. El registro institucional y las acciones de los indígenas agrupados en parcialidades no eran realidades excluyentes sino dos grillas de lectura distintas de los contornos y los principios que regían dos sistemas sociales paralelos. A nivel oficial y gubernamental, el sistema social era la provincia con sus diez reducciones de indios, y estaba articulado por la relación entre las autoridades del cabildo indígena con los curas doctrineros y con los gobernadores. Por eso no reparaba en los grupos de las parcialidades a menos que fuera evidente, necesario o que afectara el orden. En la relación entre los indígenas, en cambio, la organización en parcialidades tenía mayor relevancia y la pertenencia a alguna de ellas, tal vez asociada con el parentesco, mayor impacto en las trayectorias individuales y grupales que las que podía llegar a tener la relación con las autoridades. En suma, diría que las parcialidades correspondían a un nivel de inteligibilidad indígena, mientras que el gran conjunto homogéneo de los chiquitos tenía sobre todo entidad institucional. 


\section{BLANCOS Y NEGROS, ESPAÑOLES Y PORTUGUESES}

Los ejemplos anteriores no solo matizan la idea de la homogeneidad de los indígenas de las misiones de Chiquitos, sino que también contradicen la idea de la inmovilidad asociada con la reducción, con la fijación del domicilio y con la vida política urbana. Además de las migraciones en grupo, los documentos del período postjesuítico están plagados de referencias al movimiento permanente de sus pobladores indígenas en el interior de la provincia como así también al otro lado de la frontera con Portugal. La falta de ganado para repartir como recompensa por los trabajos comunitarios, la de bienes de fomento por la recolección de cera y el hilado de algodón, los malos tratos de los curas, la evasión de las obligaciones comunitarias, la curiosidad por los bienes que les ofrecían los portugueses, la búsqueda de alimentos por medio de la caza y la pesca en el monte son los factores a los que los informes oficiales atribuyen la huida de los indios al monte y su migración al otro lado de la frontera. En 1772 un negro que salió a la provincia de Chiquitos por las pampas de San Cristóbal, una estancia próxima a la frontera, dijo que en Cuyabá, ciudad de donde venía, había siete indios de San Rafael a quienes en Chiquitos identificaron con unos que unos años antes habían salido al monte a cazary a melear y jamás regresaron (CRM MyCh 23 XXXIII). En los primeros años del siglo XIX, Miguel Siyes, un indio del pueblo de Santa Ana que se había fugado a Casalvasco, al intentar volver a su pueblo se encontró con cuatro negros que también escapaban del reino de Portugal, con quienes Ilegó a las pampas de San Cristóbal (CRM MyCh 34 XI). En esta etapa secular del período colonial, no es la condición jesuítico-reduccional la que define el perfil socio-demográfico de la provincia, sino su carácter fronterizo. Así como la migración de los indígenas al reino portugués era moneda corriente, también lo era la recíproca de blancos y negros provenientes de aquel reino a Chiquitos.

Por los indios y los negros esclavos se volvió usual la correspondencia de reclamos mutuos de devolución entre los gobernadores de Chiquitos y el Capitán Ceneral del Mato Crosso (ACN Sala IX 20-6-7; ALP MyCh 206) ${ }^{9}$. Muchos esclavos se pasaban, como es de esperar, para obtener su libertad; los había bozales, es decir, esclavos recién sacados de su tierra de origen (ALP MyCh 97), y otros que Ilevaban mucho tiempo trabajando para comprar su libertad. Miguel Albis Ferrera era cantero, tenía 40 años y había nacido en Angola, pero vivió en Mato Grosso desde chico; se fugó porque su amo faltó a la palabra de liberarlo cuando hubiera terminado de pagar su libertad con trabajo (ALP MyCh 253). Otros decían huir de la justicia, como Juan Perera, negro a cargo de una estancia, que mató a otros cuatro que robaron una res y huyó, según dijo, por sugerencia de su amo: "toma esta escopeta y huiete para librar tu vida al reino de Castilla" (GRM MyCh 26 X). Otros esclavos Ilegaban a Chiquitos acompañando a sus amos: Juan Silva Noguera,

9 El trasfondo político de la tensión fronteriza entre ambos reinos fue tratado en la tesis de Francismar Alex Lopes de Carvalho (2012) 
natural de Cuyabá, era cabo, se desempeñaba en el destacamento fronterizo del río Barbado y desertó a Chiquitos con sus dos esclavos, descontento por haber sido mal compensado por el servicio militar que prestó a la corona y por haber querido el gobierno confiscarle sus esclavos por una deuda que tomó con particulares. De la misma manera habían llegado cuatro o cinco negros que eran esclavos de Rosalía Joaquina, casada en Cuyabá con Custodio Pires, quien se fugó con Joan Diego Barros para unirse en matrimonio en Santa Cruz. Esta ciudad era el destino de la mayor parte de los que se pasaban desde Portugal (ACN Sala IX 7-1-6). Algunos esclavos eran remitidos a La Plata y a Potosí para ser rematados en público. ${ }^{10}$ Pero hubo otros cuyo destino fue la propia provincia de Chiquitos. Simplicio Codoy, soldado pedestre, natural de San Pablo se fue del reino de Portugal en 1781 porque su comandante lo maltrataba. En 1790 aparece mencionado en una declaración por contrabando como "vecino del pueblo de Santiago", acusado de vender "lienzo, sobremesas y otros efectos de la provincia de Chiquitos" en la ciudad de Santa Cruz "diciendo que uno y otro se le han dado en satisfacción de su sueldo" (ALP MyCh 250). Efectivamente, según informan los administradores en los estados anuales de los pueblos, el sueldo de los soldados de la frontera a veces era pagado en bienes producidos en la provincia como textiles y cera, a falta de moneda. Similar es el caso de José Moreno, vecino de San Juan, cuya procedencia portuguesa no puedo asegurar, pero como prestaba servicio militar en la tropa, vivía en un pueblo de frontera y su apellido era Moreno, en certera alusión al color de su piel, es probable que haya seguido un derrotero similar al de Simplicio Codoy. Lo distintivo de José Moreno es que estaba casado con una india, Rosa Chorus, y que después de algunos años de matrimonio fue acusado de cometer adulterio con Juana Comeos, hermana de su esposa (ALP MyCh 230; GRM MyCh $27 \mathrm{XLI)}$ ).

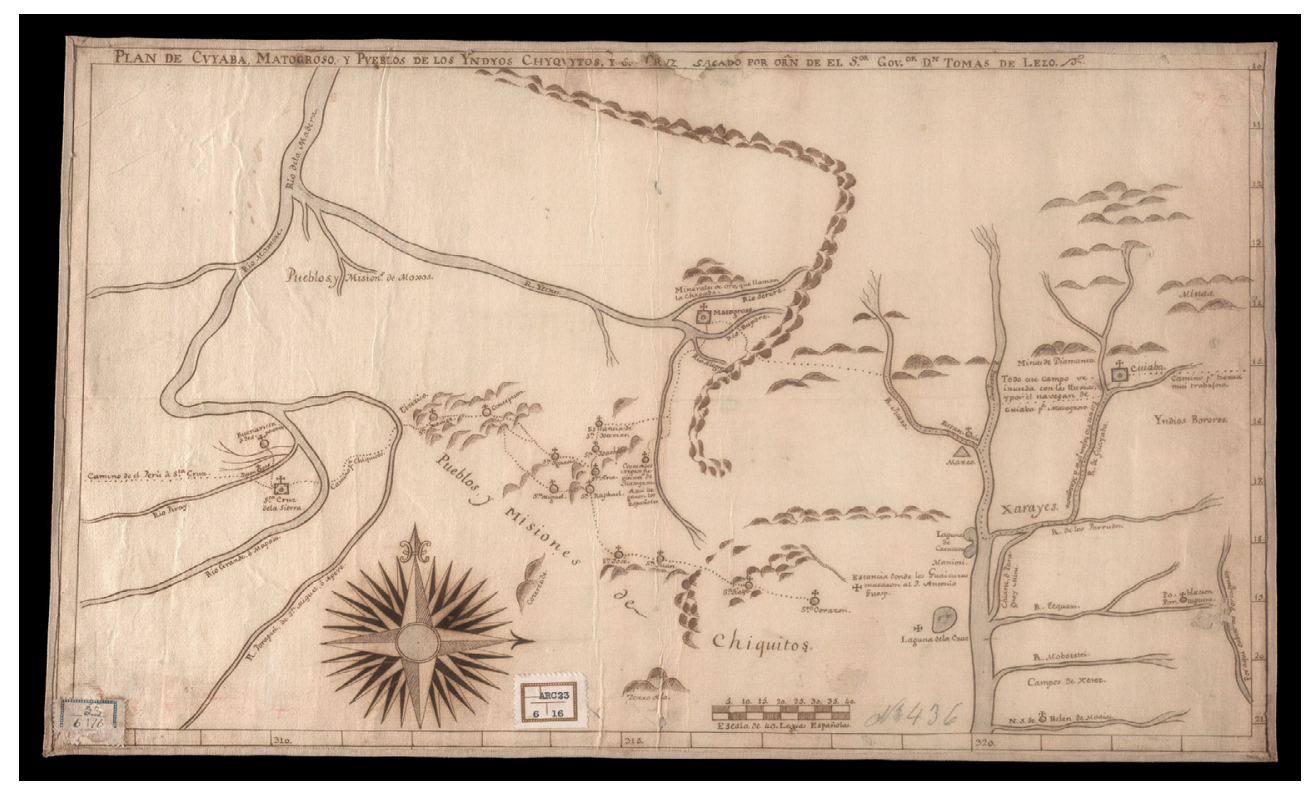

10 Por ejemplo, un moreno de nación portuguesa reclama que no lo vendan en remate público en Potosí por ser "realmente libre" natural de Río de Janeiro "y no de las costas de Guinea e hijo de padres libres" (ALP MyCh 10).

\section{Figura 1}

Plano de Cuiabá Matogroso, y pueblos de los Indios Chiquitos, y Santa Cruz. Sacado por orden del Señor Governador D. Tomas de Lezo, ca. 1778. Fuente: https://bdlb.bn.gov.br/acervo/ handle/123456789/16252. 
Así como la condición fronteriza hacía de Chiquitos un refugio para los portugueses fugitivos, para el gobierno colonial español la convertía un lugar apto para el confinamiento. En 1783 fue remitido a la frontera Faustino Fernández, desterrado por un año al destacamento militar, acusado de jugador y de cometer adulterio con la mujer de un vecino. Al año siguiente Martín Mendes y Manuel Justiniano corrieron la misma suerte, ambos condenados a servir"sin sueldo en la frontera en pena de sus delitos" (GRM MyCh 26 XIV). Francisco Rico, militar que cumplía servicio en la provincia se quejaba de que los demás soldados lo desconocieran como militar porque se rumoreaba que había cometido un asesinato en Perú (GRM MyCh 27 XLII).

Es preciso señalar que las sucesivas reglamentaciones dispuestas para la provincia limitaban y desalentaban la entrada de españoles y criollos a la provincia y el trato de éstos con los indígenas, con excepción de los curas doctrineros, los gobernadores y, a partir de la implementación del Nuevo Plan de Cobierno, con los administradores seculares (GRM MyCh 24 IV; 28 VI). Por eso, estos casos de reos confinados en la frontera eran excepciones de la norma especialmente autorizados por la Audiencia de La Plata. En la práctica, sin embargo, no eran los únicos españoles avecindados en la provincia. El caso que más llama la atención es el de Manuel Muñoz y Barbeito, oriundo de Cochabamba, pero avecindado en San José desde 1775 cuando se casó con Ignacia Sapores, india del pueblo de San Juan. En 1787 ambos enfrentaron una acusación por contrabando. En el expediente consta que Manuel Muñoz y su esposa sacaban cera, telas de algodón y rosarios de producción local para venderlos en Santa Cruz. Ese tipo de comercio estaba prohibido en el Reglamento de 1768, que disponía que fueran los curas doctrineros quienes monopolizaran el intercambio con los indígenas, tal como se hacía en la época de los jesuitas.

El sistema de la economía misional estaba organizado sobre la base de la producción de textiles y de cera para la venta en el mercado cruceño y altoperuano. La recolección de cera, el hilado del algodón y el procesamiento de ambos productos eran incentivados con la entrega de objetos que despertaban el interés de los indígenas como cuentas de vidrio, agujas, medallas, cuchillos, cuñas, telas de lana como bayeta que eran denominados "bienes de fomento" por los administradores coloniales. ${ }^{11}$ Era el gobierno de la provincia el que importaba los bienes de fomento y exportaba cera y algodón mientras que en el interior de la provincia las transacciones con los indígenas quedaban reservadas a los curas doctrineros, como representantes del gobierno. No obstante, con mucha más frecuencia que la prevista por el reglamento, los bienes de fomento escaseaban, eran usados para beneficio privado de los curas o destinados al pago de otras cosas, a falta de circulación de moneda. En esas circunstancias Manuel Muñoz y Barbeito dice haber sido autorizado por los gobernadores Barthelemí Berdugo 
y Francisco Xavier de Cañas a repartir entre los indígenas los bienes importados por él a la provincia. A cambio, obtenía los algodones hilados y la cera que de otra manera se habrían perdido porque el gobierno de la provincia no tenía con qué retribuirlos. También abasteció al gobernador, a cambio de 3000 rosarios, de bienes para repartir a los indios en una fiesta, como era costumbre. Además, dice haber recibido de José Moreno (el mismo que se había casado con Rosa Chorus) y Alejandro Baca, ambos soldados en la frontera y de José Jacinto Herrera, cura de Concepción, otros bienes de la misma clase (bayeta, frazadas, chaquiras, cuchillos, acero, cintas, lana) con los que les habían pagado sus sueldos y sínodo, respectivamente, y que Muñoz repartió a su vez entre los integrantes del cabildo de San José a cambio de algodón que "en mi casa se ha hilado con mingas que hacen de costumbre entre el vecindaje" (GRM MyCh $28 \mathrm{VIII)}$. Por último, Manuel Muñoz y su esposa Ignacia Sapores tenían una estancia donde criaban ganado que Muñoz había llevado desde Santa Cruz. El dato es por demás Ilamativo porque en el régimen de misiones las estancias y la cría de ganado se ceñían al mismo régimen comunitario que organizaba el trabajo productivo de los indios en los pueblos. No había propiedad privada de tierras ni de ganado y la carne se usaba para alimentar a quienes cumplían sus turnos de trabajo comunitario y para repartir en fiestas; las tierras de uso doméstico y familiar no tenían ganado. Por eso la estancia de Muñoz y Sapores es sugestiva y más todavía si se tiene en cuenta que la historiografía sobre la región sostiene que la liberalización de la ocupación de tierras comenzó recién en 1840 (Tonelli, 2004; Raddin, 2005). Lo cierto es que Muñoz reconocía haberle vendido una yegua al gobernador Cañas a cambio de 600 varas de lienzo producidas en la provincia y haber convidado carne y queso a los indígenas de San José, quienes a cambio le daban "sus algodoncitos" (GRM MyCh 28 VIII). En su defensa, Muñoz decía que los gobernadores lo habían autorizado a realizar esas operaciones porque era vecino de la provincia al estar casado con una india y que lo amparaban las leyes de Indias que autorizaban al trato que "pueden y deben tener libremente unos indios con otros comprando o permutándose lo que produce el sudor de sus propias cosechas" (ALP MyCh 206). En suma, Manuel Muñoz y Barbeito gozaba de una consideración especial al tener una estancia privada, de un estatuto de criollo que le permitía salir de la provincia e importar bienes de fomento y al mismo tiempo de su condición de vecino de San José y por lo tanto de cierto carácter de indígena que le permitía recurrir a las mingas con sus parientes e intercambiar bienes como si se tratara de iguales.

Pero también Ignacia Sapores declaraba "el grande alivio que al presente nos administra de tener estancia propia de ganado vacuno y caballar" y que las varas de lienzo conseguidas por la venta de la yegua y obtenidas por la minga de hilado y tejido de sus parientes, serían vendidas para que su marido le "trajese ropa 
de vestir y otros urgentes necesarios que por acá se carecen" (MyCh ALP 206). Ignacia Sapores se distinguía así de otras mujeres de su pueblo que solamente recibían el reparto de carne de las estancias del pueblo y que se vestían con el lienzo que se producía en la provincia y eventualmente con la bayeta que llegaba como recompensa por sus hilados. Es probable que las mujeres casadas con los soldados también contaran con ese acceso preferencial a los bienes llegados de afuera. A Rosa Chorus, esposa de José Moreno, y a Ignacia Sapores, casada con Manuel Muñoz y Barbeito se suma la esposa de José Mariano Carrillo, casados en Santo Corazón. Sabemos de este matrimonio por la declaración de Carrillo en una causa sobre una rebelión de los indios de ese pueblo en 1806 (MyCh GRM 34 VIII). También se conoce el caso de Pabla Someos por el expediente sobre el levantamiento de San Ignacio de 1790, quien vivía amancebada con Juan Vera y Gallo, sobrino del cura del pueblo y que se negaba a hacer vida matrimonial con su marido legítimo, lo que motivó la vergüenza y el castigo de sus hermanos (ACN Sala IX 20-6-7).

En todos los casos, es como parte de información subsidiaria de causas por rebelión, contrabando o defraudación a la administración real que llegamos a saber de la existencia de estas uniones interétnicas, matrimoniales o de hecho. Es probable que haya habido más y que la documentación oficial no sea explícita al respecto porque estaban interdictas. De cualquier modo, los casos expuestos bastan para refutar el perfil exclusivamente misional que se pretendió instaurado sin solución de continuidad desde 1691 hasta el presente. La provincia estaba habitada por indígenas, pero también por negros y por blancos que se casaban con aquellos. Los principios del régimen reduccional, aunque vigentes en la norma, en la práctica mostraban claras señales de debilidad. La condición mediterránea de Chiquitos y la consideración marginal que recibía de las autoridades coloniales del Perú, de Charcas y luego de Buenos Aires, la empujaban constantemente al desabastecimiento. Los resortes locales de la administración colonial se orientaron a subsanar esa situación, aunque eso implicara recurrir a una ilegalidad no explícita pero tal vez tolerada a causa de la misma marginalidad que la provocaba. En el mismo sentido, por su condición fronteriza con Portugal y con una economía esclavista, era casi impensable que las fugas desde ese reino no tuvieran lugar. Entonces, ambas circunstancias contribuían a la instalación de blancos y negros en Chiquitos.

Sin embargo, ninguna de ellas alcanza para explicar las uniones de los hombres negros y blancos con las mujeres indígenas. Tampoco parecen reductibles a la inmoralidad inoculada por los curas doctrineros. Las mujeres parecen haber sido parte activa e interesada en ellas. Una observación de Alcide d'Orbigny hace pensar que además contaron con el consentimiento de los hombres de su familia: "la mayor parte de los indios llega a preferir dos cosas, ante todo: su 
perro y el chico que su mujer haya tenido con un blanco. Cuando salen al campo hacen caminar a todos los hijos, en tanto que llevan en brazos al perro y sobre los hombros al hijo mestizo de su mujer" (1945: 1162). De ella se deduce, además, el lugar preferencial ocupado por los niños hijos de hombres blancos, al mismo tiempo que resulta sugerente la paridad de éstos con los perros. En efecto, es corriente en las tierras bajas la homologación de las mascotas con la alteridad. ${ }^{12}$ Por otra parte, en otro trabajo (Martínez, 2016) analicé el lugar privilegiado que ocupaban las cosas de blancos entre los indígenas de Chiquitos entre los siglos XVI y XVIII y propuse que su interés por conseguirlos había sido la base del sistema de la economía misional. El propio intercambio de objetos, el prestigio que le adjudicaban a las cosas de metal y de vidrio que conseguían de los blancos y la ostentación ornamental en contextos ceremoniales y festivos eran formas de procesar la relación con los blancos y de enfrentar una diferencia que, aunque en apariencia insalvable, podía ser superada por medio de la reciprocidad. Luego, los matrimonios de indígenas con blancos y negros bien podrían ser interpretados en la misma clave. De ser así, de tratarse efectivamente de una aptitud intrínseca de los indígenas para asimilar la diferencia interétnica, el horizonte de interpretación se amplía y el foco de atención se corre de la inmoralidad de los curas doctrineros a la predisposición de los indígenas para relacionarse e incorporar al diferente estableciendo una red de intercambio donde circulan mujeres y objetos. En ese caso, una vez más, todo un conjunto de políticas y decisiones tomadas por los agentes colonizadores y por las autoridades coloniales no bastan para explicar el resultado de su implementación entre los propios indígenas.

Considerar este papel activo en la relación con los otros no pretende, sin embargo, engrosar con un ejemplo más conceptos como "resistencia" o "agenciamiento", que encuentro plenos de una intencionalidad más asociada con formas occidentales de pensar y de actuar. Diría, en cambio, que esta forma peculiar de vincularse con la alteridad para procurar integrarla tiene efectos palpables a través de los que es posible conocer, documentos y registro oficial colonial mediante, las variaciones del pensamiento indígena, tan caro a las tierras bajas Sudamericanas, en unas circunstancias y una modalidad de conquista y de colonización, tan propias de la región andina.

\section{ETNOGÉNESIS PATRIMONIAL}

A partir de dos conjuntos de evidencia divergentes, demostré que la identidad de los indígenas de Chiquitos, asociada con el perfil jesuítico y misional y la imagen de la región que se forjó a partir de él, no solo no agota la definición de la realidad sociohistórica de la provincia luego de la expulsión de la Compañía de Jesús, sino que es por demás imprecisa. Quedó demostrada la vigencia de la cohesión de las
12 Por ejemplo, Carlos Fausto (1999) señaló el lugar privilegiado de los asistentes de los chamanes, nombrados "mascotas", en los rituales de asimilación de los cautivos a la identidad de los guerreros. Diego Villar (2005) propuso, al analizar el lugar que ocupaban los perros en la vida cotidiana y en la mitología de los pueblos de Chaco, la asociación de los perros con las diferencias interétnicas y, especialmente, las que existen entre indígenas y blancos. 
parcialidades y las situaciones concretas en las que los grupos así conformados se diferenciaban unos de otros. Propuse además que esa constatación no significaba necesariamente el reemplazo de la premisa de la homogeneización y de la etnogénesis de lo chiquito como sinónimo de jesuítico y misional, sino el reconocimiento de al menos dos esferas de registro y de acción: una más asociada con el ideal perseguido por los jesuitas y con la entidad jurisdiccional de la provincia, sus instituciones de gobierno y su inserción en el contexto colonial peruano y, luego, rioplatense; y otra que atañe a las lógicas de interacción y de organización social entre los indígenas. Por otra parte, mostré cómo el carácter reduccional fundado y mantenido por los jesuitas cedió ante una condición de mayor incidencia en el período abierto en 1768 , que es la de haber sido un espacio periférico para la dominación colonial y una región fronteriza con el reino de Portugal. La movilidad de los indígenas, las migraciones en ambos sentidos de la frontera y el asentamiento de españoles y criollos en la provincia echa por tierra cualquier pretensión de continuidad del régimen de la república de indios tal como los jesuitas decían haberlo instaurado y mantenido. Por el contrario, hemos visto cómo las uniones matrimoniales de las mujeres indígenas con soldados y comerciantes en contacto directo con el exterior de Chiquitos eran el origen de diferencias socioeconómicas entre los indígenas en la medida en que significaban el acceso preferencial a ciertos recursos que asociaban con la riqueza y con el prestigio. Al mismo tiempo sugerí que lógicas propias del pensamiento indígena pudieron estar involucradas en esas redes en las que las mujeres eran un objeto de intercambio más, y, por lo tanto, que la lectura de esos fenómenos no puede ni debe ser unívoca.

Al reconstruir la historia de chiquito y chiquitano, etnónimos con los que se conocía y se conoce actualmente a los indígenas de la región (Martínez, 2015a), anticipé esta crítica para la imagen jesuítico-misional de Chiquitos y de sus indígenas. En esa oportunidad advertí una gran dispersión de los indígenas que vivían en la provincia a partir de la segunda mitad del siglo XIX por efecto del boom del caucho y el retorno y asentamiento a principios del siglo XX como peones de estancia que no replicaba el sistema reduccional de antaño, sino que se caracterizaba por un alejamiento de los pueblos, acaparados por criollos. En esas condiciones, pensar en la continuidad de una identidad cuyos fundamentos materiales habían desaparecido, era difícil. Pero esa dificultad chocaba con la imagen jesuítica tan arraigada en la actualidad. El recorrido historiográfico y las circunstancias políticas y académicas a los que hice referencia en la primera parte de este trabajo, permiten afirmar que, así como la colonización de los jesuitas en el siglo XVIII dio lugar a una etnogénesis de alcance y definición institucional, un segundo proceso de etnogénesis que calificaré como "patrimonial" tuvo lugar a fines del siglo XX a partir de la reconstrucción de los templos y el rescate del acervo musical. En ambos casos se trató de procesos institucionales y políticos 
operados "desde arriba", en los cuales el actor social indígena no se involucró de manera activa, pero que pretendieron tener efectos directos sobre la definición de su identidad. Luego, así como propuse la coexistencia en paralelo de la definición institucional jesuítica con la lógica sociocultural de las parcialidades indígenas, cabe preguntarse acerca de la relación que pudo haber existido entre los indígenas chiquitanos y la etnogénesis patrimonial de finales del siglo $X X$, más aún porque coincide con el surgimiento de organizaciones de indígenas de las tierras bajas y del reclamo por tierras comunitarias en el marco de la aplicación de la ley INRA (Instituto Nacional de Reforma Agraria). Tal vez la perspectiva que presenté aquí sirva para pensar en variaciones a esa forma post-jesuítica de articulación de las lógicas institucionales con formas de organización y de interacción propias de los indígenas. Por lo pronto, espero haber contribuido en parte a sacar a la Chiquitania del relegamiento de los estudios americanistas.

Cecilia Martínez es Doctora en Antropología (UBA) - Licenciada en Historia (UBA) - Becaria postdoctoral del CONICET (Argentina). Sección de Etnohistoria, Facultad de Filosofía y Letras, UBA.

REFERENCIAS DOCUMENTALES Y BIBLIOGRÁFICAS

\section{Documentos citados}

Del Archivo y Biblioteca Nacionales de Bolivia (ABNB)

GRM MyCh: Fondo Gabriel René Moreno, Mojos y Chiquitos

ALP MyCh: Fondo Audiencia de La Plata, Mojos y Chiquitos

\section{Del Archivo General de la Nación (Argentina)}

ACN Sala IX 7-7-6: División Colonia Sección Cobierno, Gobierno de Santa Cruz ACN Sala IX 20-6-7: División Colonia Sección Gobierno, Gobierno de Chiquitos (1766-1809)

\section{REFERENCIAS BIBLIOCRÁFICAS}

ABERCROMBIE, Thomas

1998 Pathways of Memory and Power: Ethnography and History among an Andean People. Madison, University of Winsconsin Press. 
BARTH, Fredrik (org.)

1969 Ethnic Groups and Boundaries. The Social Organization of

Cultural Difference. Boston, Little, Brown and Company.

BOCCARA, Guillaume

2000 "Etnogénesis mapuche: resistencia y reestructuración entre los indígenas del centro-sur de Chile (siglos XVI-XVIII)". Hispanic American Historical Review, Duke, vol. 79, n. 3: 425-461.

2005 "Mundos nuevos en las fronteras del Nuevo Mundo". Nuevo Mundo Mundos Nuevos [En línea], Debates, Puesto en línea el 8 de febrero 2005, consultado el 18 de julio 2013. URL: https:// nuevomundo.revues.org/426; DOI: 104000/nuevomundo.426

CARDOSO DE OLIVEIRA, Roberto

(1971) 2003 "Identidade étnica, identificaçao e manipulaçao".

Sociedade e Cultura, Goiana, 6: 117-131.

COMBÈS, Isabelle

2006 "Coçi: hacia una relectura de la historia del oriente boliviano". In COMBÈS, Isabelle (org.). Definiciones étnicas, organización social y estrategias políticas en el Chaco y la Chiquitania. Santa Cruz de la Sierra, IFEA / Editorial El País / Servicio Holandés de Cooperación al Desarrollo. pp. 69-79.

2008 "Planchas, brazaletes y hachuelas: las rutas prehispánicas del metal andino desde el Guapay hasta el Pantanal". Revista Andina, Cusco, 47: 53-82.

2009 "La mala fe potorera. Apóstatas, donecillos y dinámicas étnicas en Chiquitos". Campos. Revista de Antropología Social, Curitiba, vol. 9, n. 2: 23-41.

2010 Diccionario étnico Santa Cruz la Vieja y su entorno en el siglo XVI. Cochabamba, Instituto de Misionología de la Universidad Católica de Bolivia.

2011 "El Paititi, los candires y las migraciones guaraníes". Suplemento antropológico, Asunción XLVI, n. 1: 1-149.

2012 "Susnik y los gorgotoquis. Efervescencia étnica en la Chiquitania (oriente boliviano)". Indiana, Berlín, 29: 201-220.

COMBÈS, Isabelle e SAICNES, Thierry

1991 "Chiri-guana: nacimiento de una identidad mestiza". In RIESTER, Jürgen (org.). Chiriguano, Santa Cruz, APCOB. pp. 25-221. 
CORTESÃO, Jaime (org.)

1955 Antecedentes do tratado do Madri. Jesuitas e bandeirantes no Paraguay (1703-1751). Manuscritos da coleção De Angelis VI, Biblioteca Nacional de Rio de Janeiro.

CISNEROS, Jaime e RICHTER, Hugo

1998 Misionesjesuíticas. La Paz, Industrias offset color.

DOCUMENTOS REFERENTES...

(c. 1561) 2008 "Documentos referentes a la fundación de Santa

Cruz de la Sierra". In JULIEN, C. Desde el oriente. Documentos

para la historia del Oriente boliviano y Santa Cruz la Vieja (1542-

1597). Santa Cruz, Fondo Editorial Municipal. pp. 94-118.

FAUSTO, Carlos

2000 "Of Enemies and Pets: Warfare and Shamanism in Amazonia". American Ethnologist, Davis, n. 24, vol. 4: 933-956.

FINOT, Enrique

1939 Historia de la conquista del Oriente Boliviano.

Buenos Aires, Librería Cervantes.

FREYER, Bärbel

2000 Los chiquitanos. Descripción de un pueblo de ñas tierras bajas orientales de Bolivia según fuentes jesuíticas del siglo XVIII. Santa Cruz, APCOB.

GANDÍA, Enrique de

1935 Historia de Santa Cruz de la Sierra. Una nueva república en Sud América.

Buenos Aires, Talleres Cráficos Argentinos de L.J. Rosso.

GARCIA RECIO, José María

1988 Análisis de una sociedad de frontera. Santa Cruz de la Sierra en los siglos XVI y XVII. Sevilla, Publicaciones de la Excma. Diputación Provincial de Sevilla.

GRUZINSKI, Serge

2007 El pensamiento mestizo. Barcelona, Paidós.

GUMUCIO, Mariano Baptista

1994 La fe viva: misiones jesuíticas de Bolivia. La Paz, Fundación Cultural Quipus. 
HOFFMANN, Werner

1979 Las misiones jesuíticas entre los Chiquitanos. Buenos Aires, Fundación para la Educación, la Ciencia y la Cultura.

JULIEN, Catherine

2005 "La historia de Alejo García". Anuario de Estudios

Bolivianos, Archivísticos y Bibliográficos, Sucre, 11.

KÜHNE, Eckart (org.)

1996 Martin Schmid 1694-1772. Las misiones jesuíticas de Bolivia.

Santa Cruz de la Sierra, Arzobispado de Santa Cruz de la

Sierra y Fundación Suiza por la Cultura "Pro Helvetia".

2007 "Las misiones de Chiquitos en el oriente boliviano: el descubrimiento de la obra del padre Martín Schmid S.]. (1694-1772) a mediados del siglo XX". In KOHUT Karl e TORALES PACHECO, María Cristina (orgs.).

Desde los confines de los imperios ibéricos. Los jesuitas de habla alemana en las misiones americanas. Madrid, Iberoamericana. pp. 327-353.

KREKELER, Birgit

1995 Historia de los chiquitanos. Santa Cruz, APCOB.

KNOGLER, Julián

(c. 1770) 1979 "Relato sobre el país y la nación de los Chiquitos". In HOFFMANN, Werner. Las misiones jesuíticas entre los Chiquitanos. Buenos Aires, Fundación para la Educación, la Ciencia y la Cultura. pp. 121-185.

LOPES DE CARVALHO, Francismar Alex

2012 Lealtades negociadas: povos indígenas e a expansão dos impérios ibéricos nas regiões centrais da América do Sul (segunda metade do século XVIII). São Paulo, tese de doutorado, Universidade de São Paulo.

MARTÍNEZ, Cecilia

2015a "Tapuy mirí, chiquitos, chiquitanos. Historia de un nombre en perspectiva interétnica". Bulletin de l'Institut français d'études andines, Lima, 44 (2): 237-258.

2015b "Las reducciones jesuitas en Chiquitos. Aspectos espacio-temporales e interpretaciones indígenas". Boletín Americanista, Barcelona, 71(1): 133-154.

2016 "Cosas de blancos entre los indios. Forma y razón de su intercambio y de su uso en Chiquitos (siglos XVI a XIX)". Indiana, Berlín, n. 33, vol. 2, en prensa. 
MATIENZO, Javier; TOMICHÁ, Roberto; COMBÈS, Isabelle; e PAGE, Carlos (orgs.)

2011 Chiquitos en las Anuas de la Compañía de Jesús (1691-1767). Cochabamba, Instituto Latinoamericano de Misionología / Editorial Verbo Divino.

MENACHO, Antonio S. J.

1987 Fundación de las reducciones de Chiquitos. Santa Cruz de la Sierra, Publicaciones de diario El Mundo.

MÉTRAUX, Alfred

1942 The Native Tribes of Eastern Bolivia and Western Matto Grosso. Washington, Bureau of American Ethnology Bulletin 134.

1944 "The Contribution of the Jesuits to the Exploration and Anthropology of South America". Mid-America. An Historical Review, 26(3): 183-191.

MORENO, Gabriel René

1888 Catálogo del Archivo de Mojosy Chiquitos. Santiago

de Chile, Imprenta Cutenberg.

ORBIGNY, Alcide d'

(1831-1835) 1945Viaje a la América Meridional. Brasil-Uruguay-

Argentina-Chile-Bolivia-Perú. Buenos Aires, Ed. Futuro.

PACE, Carlos A.

2008 "Hans Roth, un emblema de las reducciones jesuíticas de Chiquitos". Revista Hábitat, Buenos Aires, n. 55: 38-44.

2012 "El lento proceso de valoración del legado cultural de la provincia jesuítica del Paraguay". Estudios del Patrimonio Cultural, Valladolid, n. 9: 6-30.

PAREJAS MORENO, Alcides

2006 "El patrimonio cultural como factor de desarrollo: Misiones ]esuitas de Chiquitos". T'inkazos. Revista Boliviana de Ciencias Sociales, [en línea], 9, disponible en: http://www.redalyc.org/articulo.oa?id=426141563008

2007 La cultura chiquitana. Ensayosy artículos. Santa Cruz de la Sierra, Editorial La Hoguera.

PAREJAS MORENO, Alcides e SUÁREZ SALAS, Virgilio

(1992) 2007 Chiquitos: historia de una utopía. Santa Cruz de la Sierra, Fondo Editorial Cobierno Municipal Autónomo de Santa Cruz de la Sierra. 
QUEREJAZU, Pedro

1995 Las misiones jesuíticas de Chiquitos. La Paz, Fundación BHN línea editorial.

RADDING, Cynthia

2005 Paisajes de poder e identidad: fronteras imperiales en el desierto de Sonora y bosques de la Amazonía. Sucre, Fundación Cultural del banco

Central de Bolivia / Archivo y Biblioteca Nacionales de Bolivia.

RENARD CASEVITZ, France Marie; SAIGNES, Thierry; e TAYLOR, Anne Christine 1988 Al Este de los Andes. Relaciones entre las sociedades amazónicas $y$ andinas entre los siglos XV y XVII. Quito, Abya-Yala.

RIESTER, Jürgen

1967-1968 "El habla popular del oriente boliviano: el chiquito". Revista de Antropologia, São Paulo, 15-16: 172-195.

1976 En busca de la Loma Santa. La Paz, Los Amigos del Libro.

1986 Zúbaka. La Chiquitanía: visión antropológica de una región en desarrollo. Tomo I: Vocabulario Español-Chiquito y Chiquito-Español de Max Fuss-Jürgen Riester. La Paz, Los Amigos del Libro.

ROCA, José Luis

2001 Economía y sociedad en el Oriente Boliviano (siglos XVI$X X)$. Santa Cruz, Editorial Oriente S.A.

RUIZ, Juan Carlos

1998 La utopía misional es nuestra. Santa Cruz de la Sierra, Colegio de Arquitectos de Santa Cruz de la Sierra.

SCHWARTZ, Stuart e SALOMON, Frank

1999 "New Peoples and New Kinds of People: Adaptation, Readjustment, and Ethnogenesis in South American Indigenous Societies (Colonial Era)". In SALOMON e SCHWARTZ (orgs.). The Cambridge History of the Native Peoples of Americas. Volume III, South America, Part 2. Cambridge, Cambridge University Press. pp. 443-501.

SUSNIK, Branislava

1978 Los aborígenes del Paraguay l. Etnología del Chaco Boreal y su periferia (siglos XVIy XVIII). Asunción del Paraguay, Museo Etnográfico "Andrés Barbero". 


\section{STERN, Steve}

1982 Los indígenas del Perú y el desafío de la conquista española. Madrid, Alianza.

STRAK, Peter

1992 Frente a Dios y los Pozocas. Las tradiciones culturales y sociales de las reducciones jesuíticas desde la conquista hasta el presente. Fiesta Patronal y Semana santa en Chiquitos. Brandenburger Str. 15, Verlag für Regionalgeschichte.

TOMICHÁ, Roberto

2002 La primera evangelización en las reducciones de Chiquitos, Bolivia (1691-1767). Protagonistas y metodología misional. Cochabamba, Verbo Divino / Ordo Fratum Minorum Conv. / UCB.

TONELLI JUSTINIANO, Oscar

2004 Reseña histórica, social y económica de la Chiquitania. Santa Cruz, El País.

URTON, Gary

(1990) 2004 Historia de un mito. Pacariqtambo y el origen de los Inkas. Cusco, CBC.

VILLAR, Diego

2004 'Uma abordagem crítica do conceito de 'etnicidade' na obra de Fredrik Barth". Mana, Rio de Janeiro, n. 10, vol. 1: 165-192.

2005 "Indios, blancos y perros". Anthropos, Sankt

Augustin, n. 100, vol. 2: 495-506.

VILLAR, Diego e COMBÈS, Isabelle

2012 "Introducción: una aproximación comparativa a las tierras bajas bolivianas". In VILLAR, Diego e COMBĖS, Isabelle (orgs.). Las tierras bajas de Bolivia: miradas históricas y antropológicas. Santa Cruz de la Sierra: Museo de Historia UAGRM / El País. pp. 7-31.

WAISMAN, Leonardo

1991 "Música misional y estructura ideológica en Chiquitos (Bolivia)". Revista Musical Chilena, Santiago de Chile, n. 176: 43-56. 


\section{ABSTRACT}

In this article, we identify the historical, political, and academic basis of the scarcity of research focused on Chiquitos, as well as of the image associated with the Jesuit heritage. We start comparing Chiquitos with other parts of the lowlands of Bolivia, studies on Jesuit missions, and Bolivianist social history and Andean ethnohistory. Then, we propose an alternative reading on those elements that structured the social life of their inhabitants, based on the examination of late colonial evidence (1768-1809). For that, the weight of kinship on definition of significant social units among the indigenous people of Chiquitos, the socio-political, cultural, and demographic effects of being a marginal and frontier province, and Amerindian forms of assimilation of alterity are considered.

Recebido em 21 de novembro de 2016. Aceito em 19 de outubro de 2017.

\section{KEYWORDS}

Chiquitos,

Chiquitanos, South America Lowlands, Americanist Studies, Alterity, Borders 